\title{
Notiz über die Ausgleichung der Schliessungs- und Oeffnungsinductionsschläge.
}

\author{
Von
}

\section{J. Setsche now}

in St. Petersburg.

Hierzu 1 Holzschnitt.

Das bekannte Verfahren von J. Bernstein, die Stärke der Inductionsschläge auszugleichen, lässt sich etwas vervollkommnen, wenn man in die Nebenschliessung zu der inducirenden Spirale $R_{1}$ eine Rolle $R_{2}$ von gleichem Widerstande und gleicher Anzahl von Windungen auf die in der nebenstehenden Figur angegebene Weise einfübrt und die Widerstände in den Zweigen $a R_{1} b$ und $a R_{2} b$ einander gleich macht. Geschehen nun die Schliessungen und die Oeffnungen des inducirenden Kreises in der Kettenleitung acb, so heben sich die Oeffnungsextraströme in beiden Zweigen vollständig auf;

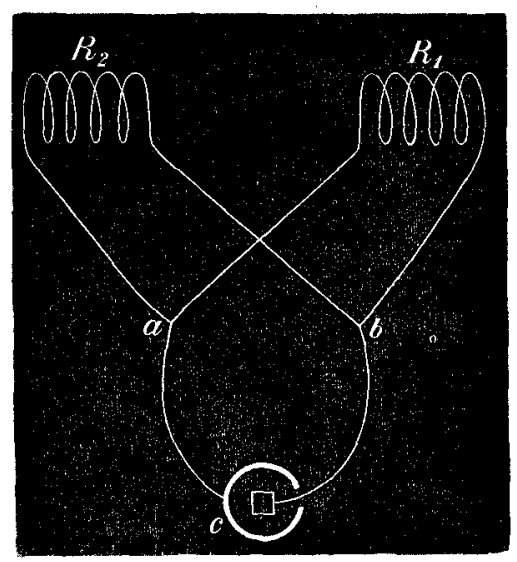
während die Schliessungsextraströme einen desto geringeren Rest in den Zweigen hinterlassen, je geringer der Widerstand in jedem Zweige im Vergleich mit dem Widerstande in der Kettenleitung $a c b$ gemacht ist.

Theoretisch muss natiurlich eine vollkommen symmetrische Einrichtung beider Zweige vortheilhaft sein; praktisch, namentlich bei den Probeversuchen am Frosehnerven, hat es sich jedoch herausgestellt, dass es so gut wie gleichgiiltig ist, ob man die neutralisirende Spirale (gleich der arbeitenden) mit einer secundären 
Rolle versieht oder nicht. Durch die Entfernung der Eisenkerne aus den Spiralen liess sich ebenfalls kein merklicher Vortheil in Bezug auf den Ausgleichungsgrad der Schläge beider Richtungen erreichen. - Stets erhält man ein kleines Uebergewicht auf Seite der Oeffnungsinductionsschläge. Uebrigens ist dasselbe schon sehr unbedeutend, wenn man bei 3 Daniells in der Kettenleitung den Widerstand der letzteren nur um den vollen Widerstand des d u Bo is'schen Reochords vergrössert. Unter diesen Bedingungen (mit den Kernen in den Spiralen) ist zugleich die Abstufung der Stärke der Inductionsschläge noch in ziemlich weiten Grenzen möglich; in meinem Inductorium betrug z. B. der betreffende Spielraum die ganze Länge der primären Spirale.

Den Ausgleichungsgrad einzelner Inductionsschläge erkennt man am einfachsten durch Reizung des Plexustheils des n. ischiadicus unweit von dem freien Querschnitt, mit Benutzung eines Stromwenders in dem Nervenkreise. Einige Augenblicke nach der Anlegung des Querschnittes ist diese Nervenstrecke bekanntlich fuir schwache absteigende Ströme viel empfindlicher als für die aufsteigenden. Dementsprechend erregen den Nerven bei der einen Lage der Wippe nur die Schliessungen, bei der anderen nur die Oeffnungen des inducirenden Kreises. 